\title{
Climate change: Sources of uncertainty in precipitation and temperature projections for Denmark
}

\author{
Ernesto Pasten-Zapata ${ }^{* 1}$, Torben O. Sonnenborg' ${ }^{1}$, Jens Christian Refsgaard ${ }^{1}$
}

RESEARCH ARTICLE | OPEN ACCESS

GEUS Bulletin Vol 43 | e2019430102 | Published online: 24 June 2019

https://doi.org/10.34194/GEUSB-201943-01-02

General Circulation Models (GCMs) are the main tools used to assess the impacts of climate change. Due to their coarse resolution, with cells of $100 \mathrm{~km} \times 100 \mathrm{~km}$, GCMs are dynamically downscaled using Regional Climate Models (RCMs) that better incorporate the local physical features and simulate the climate of a smaller region, e.g. a country. However, RCMs tend to have systematic biases when compared with local observations, such as deviations from day-to-day measurements, and from the mean and extreme events. As a result, confidence in the model projections decreases. One way to address this is to correct the RCM output using statistical methods that relate the simulations with the observations, producing bias-corrected $(\mathrm{BC})$ projections.

Here, we present the first assessment of a previously published method to bias-correct $21 \mathrm{RCM}$ projections of daily temperature and precipitation for Denmark. We assess the projected changes and sources of uncertainty. The study provides an initial assessment of the bias correction procedure applied to this set of model outputs to adjust projections of annual temperature, precipitation and potential evapotranspiration (PET). This method is expected to provide a foundation for further analysis of climate change impacts in Denmark.

\section{Material and Methods Climate models}

We analysed 21 RCMs from the Euro-CORDEX initiative (Jacob et al. 2014) driven by GCMs from the Coupled Model Intercomparison Project phase 5 (Taylor et al. 2012). Of these, 16 combinations are driven by the greenhouse gas concentration scenario (Representative Concentration Pathway) RCP 8.5 and five are driven by RCP 4.5 (Table 1). RCPs are based on a review of existing scientific literature considering different descriptions of future socioeconomic conditions, technological development, the environment, climate and emission of greenhouse gases and aerosols (Moss et al.
2010). RCP 8.5 represents a rising radiative forcing reaching $8.5 \mathrm{~W} / \mathrm{m}^{2}$ by 2100 whereas RCP 4.5 represents a scenario of stabilised radiative forcing at $4.5 \mathrm{~W} / \mathrm{m}^{2}$, both relative to preindustrial levels (van Vuuren et al. 2011). The RCM daily outputs were remapped using the Climate Data Operators - a collection of command line operators to analyse climate model data (Schulzweida 2019) - to match the grids of the observed temperature $(20 \mathrm{~km})$ and precipitation $(10 \mathrm{~km}) \mathrm{ob}$ tained from the Danish Meteorological Institute (DMI). We remapped temperature using a bilinear interpolation and a conservative interpolation for precipitation.

\section{Bias-correction}

Precipitation and temperature data were bias-corrected using a distribution-based scaling method, whereby daily simulations were fitted to daily observations, as described by Seaby et al. (2013). We used the double gamma distribution with a cut-off threshold set to the 90th percentile to bias-correct precipitation, and a normal distribution for temperature. Bias correction has limitations. For example, the correction depends on the training period used to define the distribution parameters that will be used to bias-correct the simulated precipitation and temperature (Lafon et al. 2013), biases associated with the driving data (Maraun 2016) and any possible alterations in the signal of change in the projection (Maraun 2013). Bias correction also assumes stationarity in the trained parameters (Chen et al. 2015). These and other limitations have been discussed in detail by Maraun $\&$ Widmann (2018). In our method, we used gridded observations from 1991 to 2010 as the training dataset. The parameters obtained during this training period were used to generate BC time series from 1971 to 2100 . The correction method was cross-validated using a five-fold method (Maraun et al. 2015), where five non-overlapping periods of equal length are defined. Four periods were used to train the parameters and then the parameters were used to bias-correct the remaining 
Table 1. Projected change in the mean annual temperature $(T)$, precipitation $(P)$ and potential evapotranspiration (PET)

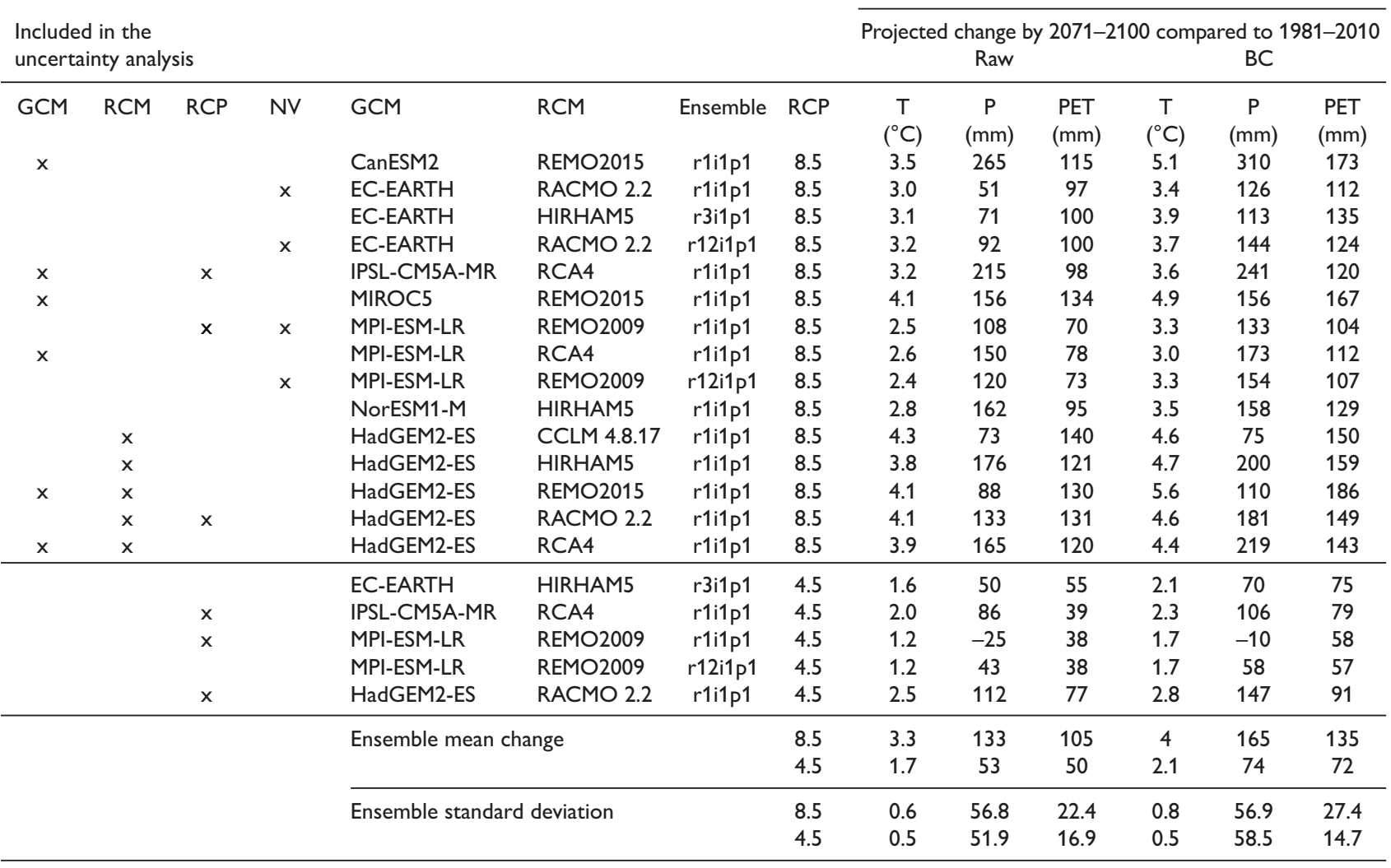

Changes are for 2071-2100, relative to the 1981-2010 reference period for the uncorrected (raw) and bias-corrected (BC) simulations. GCM: General Circulation Model. RCM: Regional Climate Model. RCP: Representative Concentration Pathway. NV: natural variability.

period. Following this approach, cross-validated time series were developed for the entire period.

\section{Potential evapotranspiration (PET)}

PET was estimated using the Oudin formula (Oudin et al. 2005), which uses temperature as the only climate input. The formula accurately reproduces the annual accumulated PET over Denmark when compared to observations, but they are offset from the observed monthly distributions, and a correction parameter needs to be applied. Here, we estimated daily PET using the climate model temperature (uncorrected and $\mathrm{BC})$ as the input and applied the correction parameter.

\section{Results and discussion}

We validated the bias correction method by comparing how well the uncorrected and BC models simulate the observed mean annual temperature and precipitation. Then, we assessed the projected changes in temperature, precipitation, and PET by the end of this century for the whole ensemble and for each individual combination of GCM and RCM. We then assessed the contribution of individual sources of uncertainty in the projections. Finally, we assessed the spatial distribution of the projected change for mean annual precipitation under RCP 8.5 by the end of the century along with a measure of its uncertainty. Here, we assess the change in precipitation only, as its variation throughout the country is larger than that of temperature and PET.

\section{Bias-corrected results}

Mean annual temperature biases range from $-1.2^{\circ} \mathrm{C}$ to $+1.0^{\circ} \mathrm{C}$ in the uncorrected models and $-0.1^{\circ} \mathrm{C}$ to $+0.3^{\circ} \mathrm{C}$ in the $\mathrm{BC}$ models (data not shown). The mean annual precipitation $(857 \mathrm{~mm})$ biases range from $-26 \%$ to $+39 \%$ for the uncorrected models and between $-3 \%$ and $+5 \%$ for the BC simulations. Even though PET is not a direct output of the climate models, we assessed the biases associated with it using uncorrected and $\mathrm{BC}$ temperature data as the input to the Oudin formula. The biases associated with mean annual 
A. Temperature, RCP 4.5

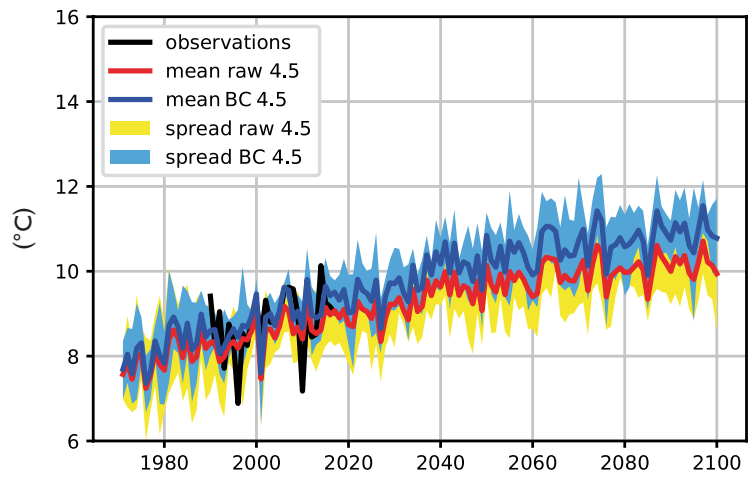

C. Precipitation, RCP 4.5

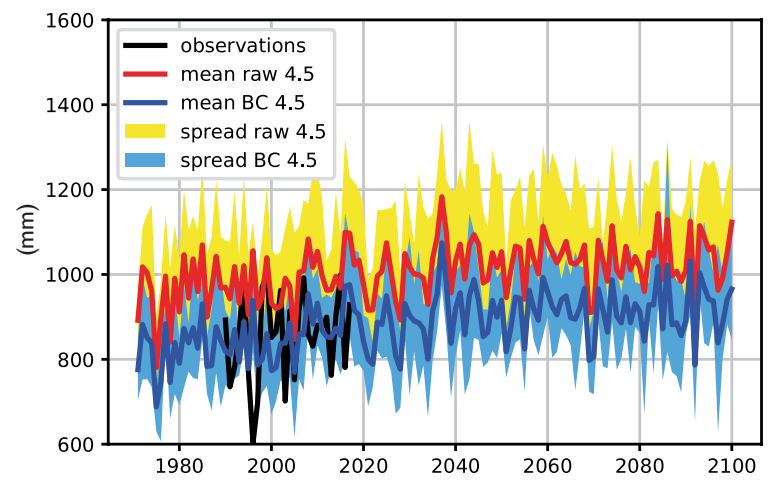

E. Potential evapotranspiration, RCP 4.5

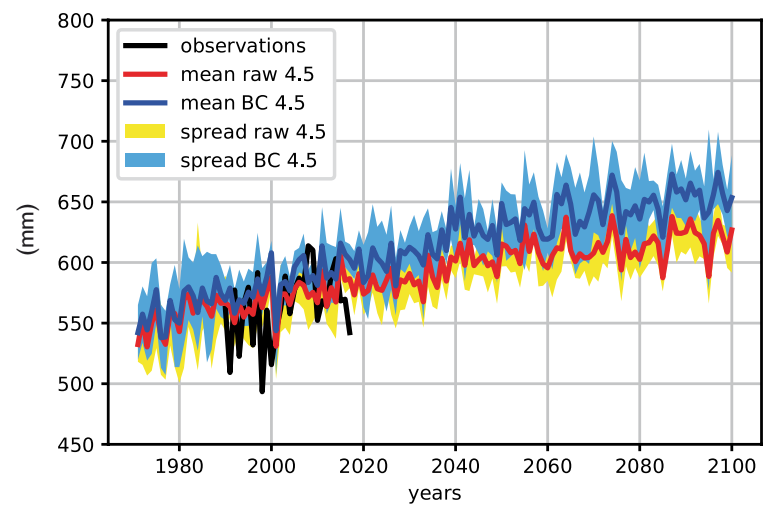

B. Temperature, RCP 8.5

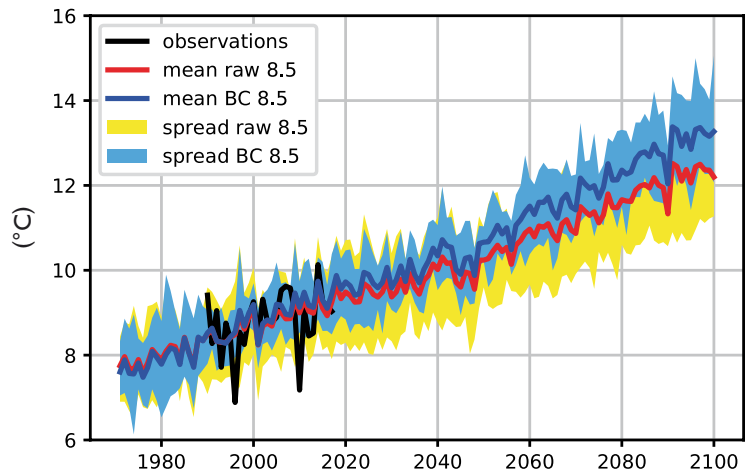

D. Precipitation, RCP 8.5

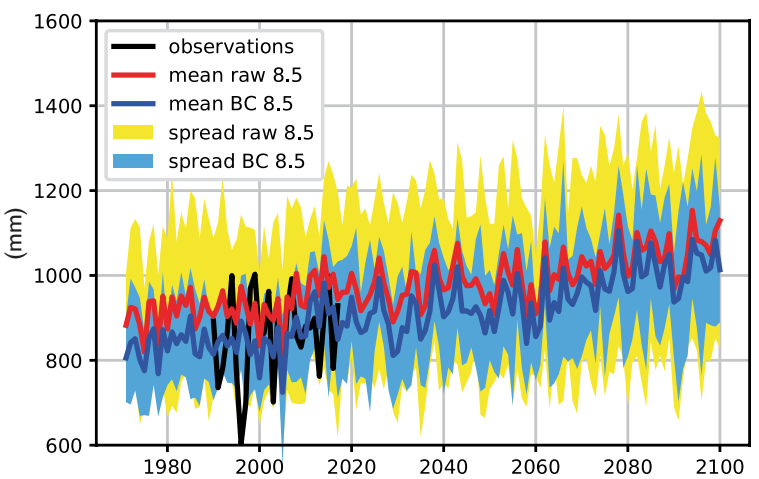

F. Potential evapotranspiration, RCP 8.5

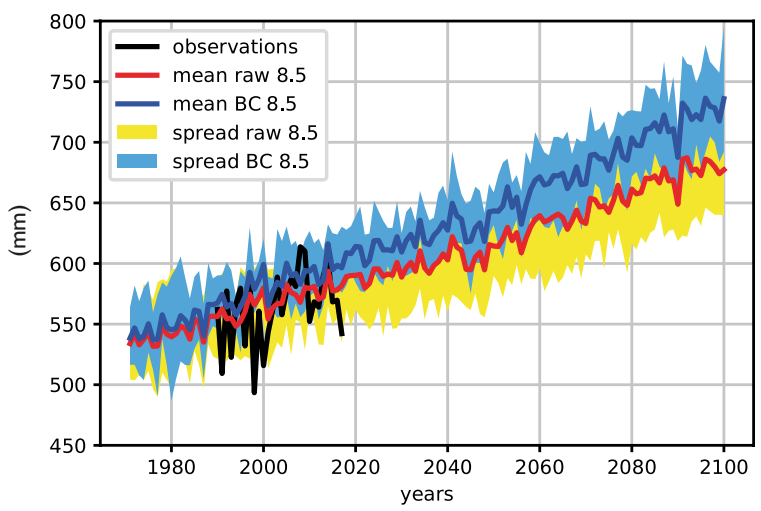

Fig 1. Observations and uncorrected (raw) and bias-corrected (BC) projections under two RCP scenarios. Mean annual temperature under A: RCP 4.5 and B: RCP 8.5. Mean annual precipitation under C: RCP 4.5 and D: RCP 8.5. Mean annual potential evapotranspiration under E: RCP 4.5 and F: RCP 8.5.

PET $(564 \mathrm{~mm})$ range from $-6 \%$ to $+8 \%$ in the uncorrected models and $+2 \%$ to $+5 \%$ in the $\mathrm{BC}$ models.

\section{Projected changes}

The $\mathrm{BC}$ simulations project higher temperatures and PET compared to the uncorrected simulations (Fig. 1). In contrast, the uncorrected models project higher precipitation than the BC models. The change in temperature and PET by the end of the century is larger when driven by RCP 8.5 compared to RCP 4.5. The same is true for precipitation, but the difference between the two RCPs is small.

When driven by RCP 4.5, the mean of the uncorrected models projects an increase in temperature of $1.7^{\circ} \mathrm{C}$ by the end of the century, while the $\mathrm{BC}$ simulations project an increase of $2.1^{\circ} \mathrm{C}$. Under RCP 8.5, the uncorrected ensemble mean projects an increase of $3.3^{\circ} \mathrm{C}$ and the $\mathrm{BC}$ models project an increase of $4^{\circ} \mathrm{C}$ (Table 1$)$. 
Table 2. Signal to noise ratio for temperature $(T)$ and precipitation $(P)$

\begin{tabular}{lcccccccc}
\hline & \multicolumn{2}{c}{$\mathrm{T}\left({ }^{\circ} \mathrm{C}\right)$} & \multicolumn{2}{c}{ Raw } & \multicolumn{2}{c}{$\mathrm{P}(\mathrm{mm})$} & $\mathrm{T}\left({ }^{\circ} \mathrm{C}\right)$ & $\mathrm{BC}$ \\
\hline Uncertainty source & $2041-2070$ & $2071-2100$ & $2041-2070$ & $2071-2100$ & $2041-2070$ & $2071-2100$ & $2041-2070$ & $2071-2100$ \\
GCM & 5.7 & 5.7 & 1.2 & 2.0 & 6.3 & 6.3 & 2.0 & 2.7 \\
RCM & 15.3 & 19.9 & 2.4 & 2.8 & 9.9 & 10.1 & 1.8 & 2.5 \\
RCP & 2.6 & 2.6 & 1.7 & 1.4 & 3.2 & 3.0 & 2.1 & 1.6 \\
NV & 5.0 & 42.0 & 12.9 & 4.5 & 6.3 & 16.1 & 3.7 & 11.4 \\
\hline
\end{tabular}

GCM: General Circulation Model. RCM: Regional Climate Model. RCP: Representative Concentration Pathway. NV: natural variability.

Under RCP 4.5, uncorrected models project an increase in inland precipitation of $53 \mathrm{~mm} / \mathrm{yr}$ by the end of the century, in contrast to the $76 \mathrm{~mm} / \mathrm{yr}$ projected by the BC models. Under RCP 8.5, the uncorrected ensemble projects an increase of $133 \mathrm{~mm} / \mathrm{yr}$ by the end of the century whilst the $\mathrm{BC}$ ensemble projects an increase of $165 \mathrm{~mm} / \mathrm{yr}$. The bias-correction method applied here, clearly changes the climate signal from the combined GCM-RCM. This contrasts with other bias-correction methods, such as the delta change bias-correction, which has no such effect.

PET projections follow a similar pattern as temperature, with larger increases projected by the $\mathrm{BC}$ models compared to the uncorrected projections, and with the largest increase by the end of the century. Notably, the ensemble change for PET is always lower than the change projected for precipitation.

Table 1 shows the projected changes in mean annual temperature, PET and precipitation for individual models by the end of the century. Clusters are observed, such as models that project a warmer (e.g. CanESM2-REMO2015 and all RCMs driven by HadGEM2-ES under RCP 8.5) or a wetter climate (CanESM2-REMO2015, IPSL-CM5A-MR-RCA4, HadGEM2-ES-HIRHAM5 under RCP 8.5) compared to the ensemble mean. Further clusters emerge among models that project an increase in water stress (where the increase in $\mathrm{PET}$ is larger than the increase in precipitation), such as $\mathrm{Had}-$ GEM2-ES-CCLM and HadGEM2-ES-REMO2015 when driven by RCP 8.5 . These clusters can provide insights into the impacts of climate change on Danish water resources.

\section{Uncertainty of the projections}

The ensemble spread from the $\mathrm{BC}$ simulations is smaller than the spread of the uncorrected models for temperature and PET when driven by RCP 8.5. For precipitation, the ensemble spread decreases for both RCPs. The standard deviation of the mean annual precipitation from 2071 to 2100 is reduced by bias-correction from $166 \mathrm{~mm}$ to $122 \mathrm{~mm}$ for RCP 4.5 and from $211 \mathrm{~mm}$ to $139 \mathrm{~mm}$ for RCP 8.5 .
The spread or 'uncertainty' in projections comes from the choice of GCM, RCM or RCP and the natural variability expressed in the models. To assess the contribution of each source of uncertainty to the overall spread of projections, we analysed the signal-to-noise ratio (SNR) of the precipitation and temperature projections driven by RCP 8.5 for the middle and end of the century (Table 2). The SNR of an ensemble is defined as the projected mean divided by the standard deviation of the ensemble. Thus, a low SNR implies that the uncertainty of the projection is high.

Our analysis has some limitations, which we acknowledge here. First, the full range of all possible combinations of GCMs and RCMs were not available for the uncertainty analysis. Second, some of the available GCM-RCM combinations were run with different initial conditions and third, not all RCMs are driven by the same GCMs. Considering these limitations, we used the GCM-RCM combinations driven by HadGEM2-ES to assess RCM uncertainty. GCM uncertainty was estimated by averaging the output of the REMO2015 and RCA4 RCMs (each one driven by three different GCMs). RCP uncertainty was evaluated using the GCM-RCM combinations available for both scenarios. Uncertainty associated with natural variability was assessed using simulations with two different initial conditions (Table 1).

For temperature, the largest source of uncertainty in the uncorrected models is the choice of RCP scenario used. The uncertainty associated with natural variability is largest by the middle of the century and then reduces. Finally, the uncertainty associated with the GCM is larger than that of the RCM, which represents the smallest source of uncertainty, overall. These results are similar to the findings of Hawkins $\&$ Sutton (2011) for projections of global mean temperature.

For precipitation, the choice of GCM and RCP provides the largest sources of uncertainty by the middle of the century and the end of the century, respectively. The next largest source of uncertainty is the RCM followed by natural variability. Hawkins \& Sutton (2011) estimated that the model uncertainty is larger than the uncertainty associated with 


\section{A. Uncorrected ensemble, mean change}

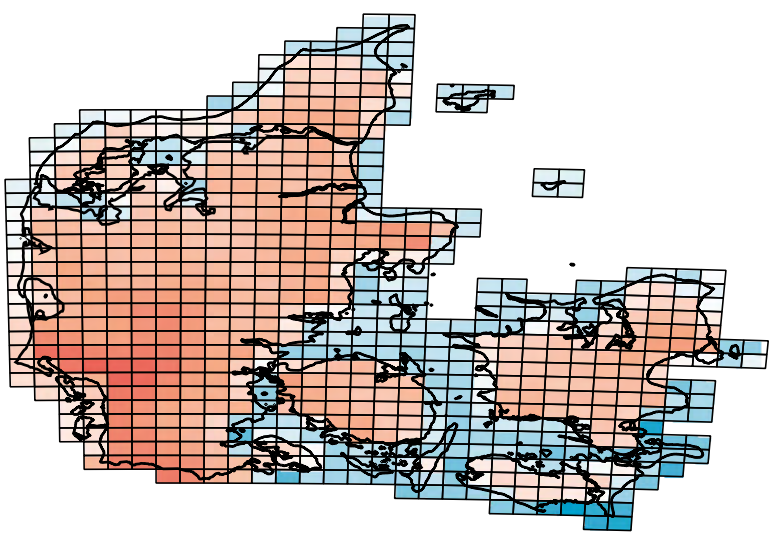

C. Uncorrected ensemble, standard deviation d)

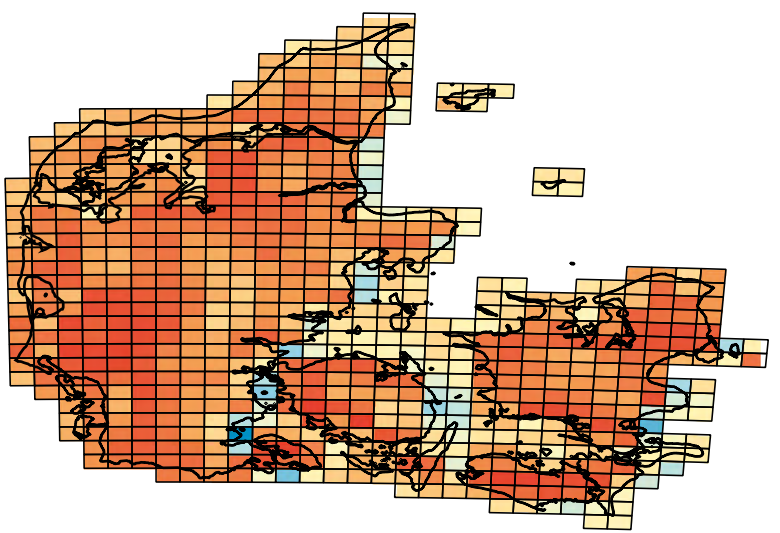

B. Bias-corrected ensemble, mean change

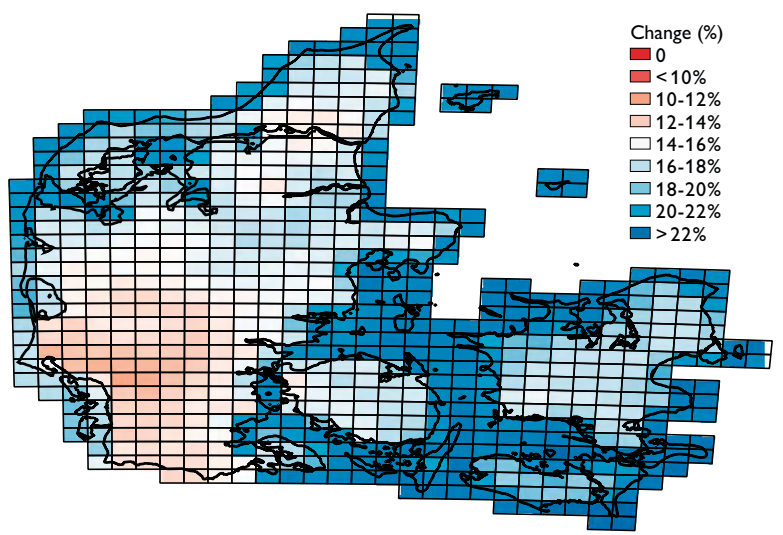

D. Bias-corrected ensemble, standard deviation

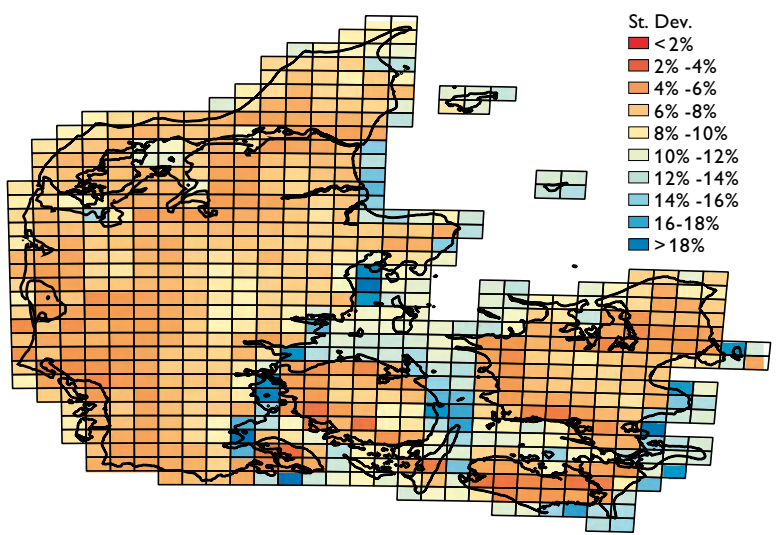

Fig. 2. RCP 8.5 annual precipitation change (\%) by the end of the century (2071-2100) relative to the 1981-2010 reference period for the A: uncorrected and B: bias-corrected ensemble. Standard deviation for the C: uncorrected and D: bias-corrected ensemble.

the emission scenario, with little influence from natural variability. This agrees with our results, but in Denmark, RCP becomes the largest source of uncertainty by the end of the century.

Bias-correction does not alter the uncertainty associated with the temperature projections. However, bias correction of the precipitation data causes the choice of RCM to become the largest source of uncertainty by the middle of the century, and the second largest source of uncertainty by 2100 .

\section{Spatial distribution of the projections}

Precipitation is projected to increase throughout Denmark, but the relative magnitude of this change varies according to location. The projected change in the uncorrected models ranges from $+10 \%$ to $+22 \%$ by the end of the century, compared to the 1981-2010 reference period (Fig. 2A), whereas the $\mathrm{BC}$ projections range from $+12 \%$ to $+31 \%$ (Fig. $2 \mathrm{~B}$ ). Similarly, the standard deviation of the uncorrected projections varies between $+3 \%$ and $+19 \%$ and between $+4 \%$ and $+21 \%$ for the BC models. Bias correction generally leads to even higher projections of precipitation by the end of the century. The standard deviation is less effected.

The spatial distribution of change is relatively homogeneous over inland Denmark. Variations in the projections are mostly observed on the coast cells in both the uncorrected and $\mathrm{BC}$ models. However, after bias-correction this variation along the coast increases as indicated by the large standard deviation. This could be due to the interpolation method in the observation dataset, which lacks point data in the coast cells.

\section{Outlook}

This study provides an overview of the bias-corrected projections from current state-of-the-art climate models, which were not previously available for Denmark. By identifying the contribution of each uncertainty source and providing 
the projected change from the ensemble and from each individual model, we provide a basis upon which to plan future assessments of the impacts of climate change on Danish water resources. The data represent a useful input to the Danish National Water Resources Model (DK-Model) for the analysis of climate change impacts. However, this initial analysis is aggregated for the whole of Denmark and projections vary across the country. Further research will focus on assessing monthly and seasonal changes in the projections as well as using these post-processed models to evaluate the projected impacts on Danish hydrology.

\section{Acknowledgements}

This research was funded by the AquaClew project and the Danish Agency for Data Supply and Efficiency (The Danish Ministry of Energy, Utilities and Climate). We thank DMI for providing the gridded observations and the Euro-CORDEX models for the Danish domain.

\section{References}

Chen, J., Brissette, F.P. \& Lucas-Picher, P. 2015: Assessing the limits of bias-correcting climate model outputs for climate change impact studies. Journal of Geophysical Research: Atmospheres 120, 1123-1136. https://doi.org/10.1002/2014jd022635

Hawkins, E. \& Sutton, R. 2011: The potential to narrow uncertainty in projections of regional precipitation change. Climate Dynamics 37, 407-418. https://doi.org/10.1007/s00382-010-0810-6

Jacob, D. et al. 2014: EUROCORDEX: new high-resolution climate change projections for European impact research. Regional Environmental Change 14, 563-578. https://doi.org/10.1007/s10113-0130499-2

Lafon, T., Dadson, S., Buys, G. \& Prudhomme, C. 2013: Bias correction of daily precipitation simulated by a regional climate model: a comparison of methods. International Journal of Climatology 33, 1367-1381. https://doi.org/10.1002/joc.3518
Maraun, D. 2013: Bias correction, quantile mapping, and downscaling: Revisiting the inflation issue. Journal of Climate 26, 2137-2143. https://doi.org/10.1175/jcli-d-12-00821.1

Maraun, D. 2016: Bias correcting climate change simulations - a critical review. Current Climate Change Reports 2, 211-220. https://doi. org/10.1007/s40641-016-0050-x

Maraun, D., Widmann, M., Gutiérrez, J.M., Kotlarski, S., Chandler, R.E., Hertig, E., Wibig, J., Huth, R. \& Wilcke, R.A. 2015: VALUE: A framework to validate downscaling approaches for climate change studies. Earth's Future 3, 1-14. https://doi.org/10.1002/2014ef000259

Maraun, D. \& Widmann, M. 2018: Statistical downscaling and bias correction for climate research. Cambridge: Cambridge University Press. https://doi.org/10.1017/9781107588783

Moss, R.H. et al. 2010: The next generation of scenarios for climate change research and assessment. Nature 463, 747-756. https://doi. org $/ 10.1038 /$ nature 08823

Oudin, L., Hervieu, F., Michel, C., Perrin, C., Andréassian, V., Anctil, F. \& Loumagne, C. 2005: Which potential evapotranspiration input for a lumped rainfall-runoff model? Part 2 - Towards a simple and efficient potential evapotranspiration model for rainfall-runoff modelling. Journal of Hydrology 303, 290-306. https://doi.org/10.1016/ j.jhydrol.2004.08.026

Schulzweida, U. 2019: CDO User Guide, Version 1.9.6. https://doi. org $/ 10.5281 /$ zenodo. 2558193

Seaby, L.P., Refsgaard, J.C., Sonnenborg, T.O., Stisen, S., Christensen, J.H. \& Jensen, K.H. 2013: Assessment of robustness and significance of climate change signals for an ensemble of distribution-based scaled climate projections. Journal of hydrology 486, 479-493. https://doi. org/10.1016/j.jhydrol.2013.02.015

Taylor, K.E., Stouffer, R.J. \& Meehl, G.A. 2012: An overview of CMIP5 and the experiment design. Bulletin of the American Meteorological Society 93, 485-498. https://doi.org/10.1175/bams-d-11-00094.1

Van Vuuren, D.P. et al. 2011: The representative concentration pathways: an overview. Climatic change 109, 5-31. https://doi.org/10.1007/ s10584-011-0148-z

\section{How to cite}

Pasten-Zapata, E., Sonnenborg, T.O. \& Refsgaard, J.C. 2019: Climate change: Sources of uncertainty in precipitation and temperature projections for Denmark. Geological Survey of Denmark and Greenland Bulletin 43, e2019430102.https://doi.org/10.34194/GEUSB-201943-01-02

\footnotetext{
${ }^{*}$ Corresponding author: Ernesto Pasten-Zapata |E-mail: epz@geus.dk

${ }^{1}$ Geological Survey of Denmark and Greenland (GEUS), Øster Voldgade 10, DK-1350, Copenhagen K, Denmark.
} 